\title{
Prevalence assessment of gastrointestinal parasitic infections among goats in Giza Governorate, Egypt
}

\author{
Noha M. F. Hassan*, Tarek K. Farag, Nadia M. T. Abu El Ezz and Hala A. A. Abou-Zeina
}

\begin{abstract}
Background: Gastrointestinal parasitic diseases remain an obstacle in goat industry in Egypt and worldwide. This study was conducted for assessing the prevalence of the gastrointestinal parasitic infections among goats in Giza Governorate, Egypt. To fulfill this study, examination of 225 fecal samples of live animals kept by small holders was done, as well as postmortem investigation of 135 random slaughtered goats' gastrointestinal tracts was achieved during the period from March to May 2018.

Results: The examination of fecal samples revealed that overall prevalence of gastrointestinal parasitic infections among goats was $89.33 \%$. The respective prevalence of kids, yearling, and adults were $89.16 \%, 98.44 \%$, and $82.05 \%$. The common parasitic infections prevalent were Coccidia spp. (76.89\%), Entamoeba spp. (26.22\%), Moniezia spp. (18.22\%), Strongyle group (12.88\%), Trichuris ovis (5.33\%), Strongyloides papillosus (3.55\%), Balantidium coli (2.66\%), and Fasciola spp. (0.89\%), successively. Mixed infection was recorded as $61.77 \%$ in the examined goats. The present study showed that the prevalence of infection by Coccidia spp., Moniezia spp., and Strongyle group was the highest in the yearling age group. In contrary, the infection prevalence of Entamoeba spp. was significantly high in the adult age group. No significant difference was found relying on the sex of the goats. The post-slaughtering finding showed that Haemonchus contortus was the most prevalent nematode followed by Trichuris ovis and Trichostrongylus axei. Remarkable infection percentage of Taenia hydatigena metacestode (Cysticercus tenuicolli) is recorded in the omentum of the intestine (31.85\%).

Conclusions: The present study provides basic data about the most prevalent GIP diseases among goats in Giza Governorate, Egypt, which required for evaluation of the followed management and control measures. This work elicited the risk of transmission of some zoonotic diseases via goats. Fecal examination and postmortem finding-based surveys remain of choice particularly in the deprived investigating areas.
\end{abstract}

Keywords: Prevalence, Gastrointestinal parasitic infections, Goats, Egypt

\section{Background}

Goats are deemed to be one of the most essential species of livestock worldwide especially in tropical areas and in dry zones (Di Cerbo et al. 2010). Goat production is a fundamental sector in Egypt where many native prolific breeds are reared especially Baladi for meat production and the Nabi (or Zaraibi) for milk production (AboulNaga et al. 2012). Parasitic diseases are involved among the major constraints of poor goat health and productivity

\footnotetext{
* Correspondence: Nohamhassan555@yahoo.com Department of Parasitology and Animal Diseases, National Research Centre (NRC), 33 Bohouth street, P.O. Box: 12622, Dokki, Giza, Egypt
}

(Kusiluka et al. 1998) and might result in weight losses of 6-12 kg per animal per year and $40 \%$ mortality rates in goat herd (Githigia et al. 2001). Infections of gastrointestinal helminths and enteric protozoan parasites among goats are implicated in serious economic losses including morbidity and mortality, mostly for young animals (Waller 1999; Badran et al. 2012; Majeed et al. 2015). A related study reported that among the gastrointestinal parasites (GIP), Strongyle nematodes are considered as one of the extremely pathogenic and economically significant parasites affecting small ruminants (Perry et al. 2002; Jurasek et al. 2010). Indeed, goats act as intermediate host for Taenia hydatigena which is considered of economical and 
clinical importance than the adult tape worm infection (Smith and Sherman 1994; Oryan et al. 2012). Moreover, coccidiosis caused by genus the Eimeria is one of widely spread parasitic diseases either clinically or subclinically among small ruminants in Egypt and all over the world (Agyei et al. 2004; Gadelhaq et al., 2015; Majeed et al. 2015). Coccidian parasites contribute to enteric disease particularly in young or goats under stress in poor farm conditions, which lead to high mortality rate among goat kids (Ratanapob et al. 2012). Several studies revealed that Balantidium coli (B. coli) and Entamoeba spp. infections are of public health significance and could cause zoonotic transmission to the human being (Mhoma et al. 2011; Elmadawy and Diab, 2017). Studying the intensity of parasitic infection prevalence remains a need for animal's proper management and control measures. In Egypt, monitoring of helminthic and protozoal infections and their prevalence has been recorded among small ruminants (Soliman and Zalat 2003; El-Shahawy 2016; Sultan et al. 2016; Elmadawy and Diab 2017; Mohamaden et al. 2018). It is supposed that determination of the most prevailing GIP is imperative to shrink the economic losses in goat industry. So the current study is assigned to stand on the prevalence of the GIP diseases among goats in Giza Governorate, Egypt, and consequently, that might be aiding in construction the foundation required for efficient control approach.

\section{Material and methods}

\section{The study locality and subjects}

The study was conducted at different localities in Giza Governorate, Egypt $\left(29^{\circ} 16^{\prime} \mathrm{N} 29^{\circ} 40^{\prime} \mathrm{E} / 29.26^{\circ} \mathrm{N} 29.67^{\circ}\right.$ E), from March to May 2018. Mostly, the goat flocks are reared by the free-range system, where animals graze freely all over the country as no regulation of animal movement is present in Egypt (Aidaros 2005). Two hundred and twenty-five live goats during the period from March to May 2018 at spring season were classified according to the age and sex. The experiment included 116 females and 109 males, of them 83 kids, 64 yearlings, and 78 adults. A postmortem study was also performed for 135 slaughtered goats.

\section{Clinical inspection and fecal samples collection}

Clinical examination was carried out thoroughly for all the animals under experiment (Radostits et al. 2000). The animals which received previous treatment were excluded. The fecal samples were collected in the morning directly from the rectum of each animal using sterile disposable glove and placed in a plastic bag. The date of sampling, sex, age, and identifying number were achieved for each animal. The samples were transferred directly at the same day of collection in an airtight box cooler with dry ice packs to the Laboratory of Parasitology and Animal
Diseases Department, National Research Centre, and then stored at $4{ }^{\circ} \mathrm{C}$ for a maximum of $48 \mathrm{~h}$ before analysis.

\section{Fecal examination}

Each fecal sample was checked utilizing concentration sedimentation and concentration floatation techniques as the method adopted by Soulsby (1986). Identification of parasite stages was relied on their morphological characteristics as reported by Urquhart et al. (1996) using $\times 10$ and $\times 40$ magnification.

\section{Collection and examination of GITs}

The examination of GITs, parasites collection from GIT contents, and washings were performed immediately after slaughtering of the animals according to Taylor (1934). Identification of the parasites was done through their morphological features (Rahman et al. 1975, Soulsby 1982).

\section{Statistical analysis}

The prevalence was estimated as a percentage of number of animals infected in the total number of animals examined. The significant difference analysis was proceeded using the chi-square $\left(\chi^{2}\right)$ test by statistical computer package for social science (SPSS) version 15.0 (SPSS Inc., Chicago, IL), and $p<0.05$.

\section{Results}

The clinical examination of 225 goats located at the studied areas in Giza Governorate revealed that 176 $(78.22 \%)$ goats were apparently healthy, while 49 $(21.78 \%)$ of them suffered from diarrhea, general weakness, inappetence to off food, dehydration, weight loss, and depression. The coccidian-infected goats were manifested with watery diarrhea with clumps of mucous and sometimes changes in the color of feces to yellow or brown in kids and hemorrhagic diarrhea in adult.

The fecal examination of the goats proved that the overall prevalence of GIP infection was 89.33\% (201/ $225)$, reaching $92.66 \%(101 / 109)$ of males and $86.21 \%$ $(100 / 116)$ of females being infected by GIP. Fecal examination findings are presented in Figs. 1, 2, and 3. Mixed infection was recorded as $61.77 \%(139 / 225)$ in the examined goats, $65.52 \%(76 / 116)$ for the females and $57.79 \%$ $(63 / 109)$ for the males. The over all prevalence of GIP in kids, yearlings and adults were 89.16\% (74/83), 98.44\% $(63 / 64)$ and $82.05 \%(64 / 78)$ successively.

The examination of fecal samples exhibited that most of the investigated animals $173 / 225$ (76.89\%) had mild to severe coccidian infection (Eimeria spp.). Different Eimeria species were detected. Significant association $(P<0.05)$ between the prevalence of coccidian infections and the age groups was observed as illustrated in Table 1. The highest prevalence of coccidian infection was observed in 


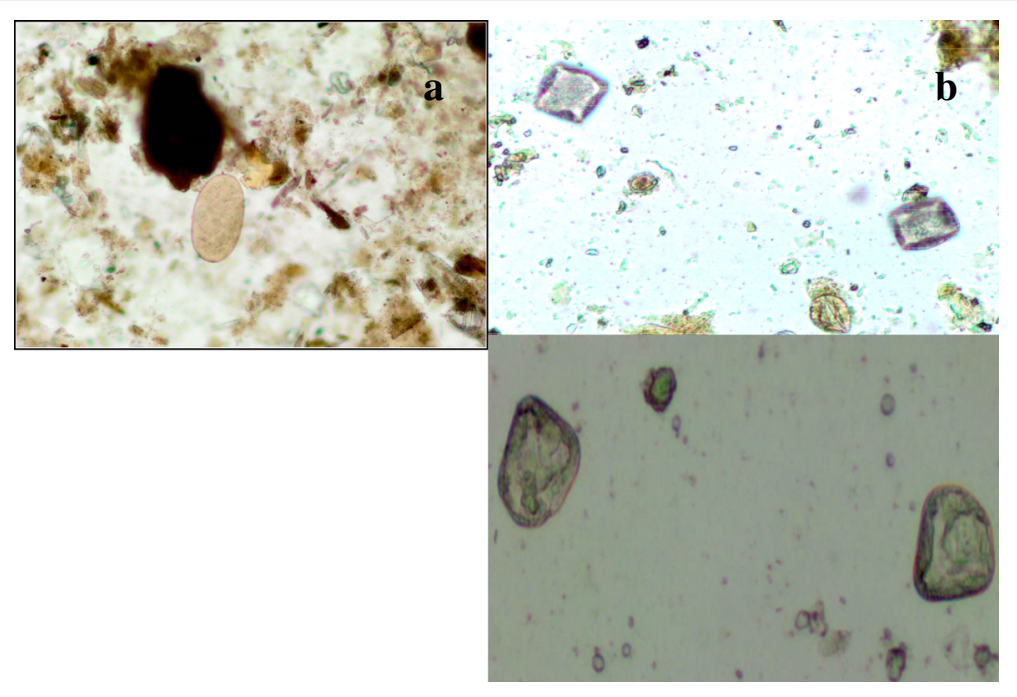

a Fasciola spp., b Monezia spp.

Fig. 1 Shapes of different trematodes and cestodes eggs found in the examined goats. a Fasciola spp., b Moniezia spp.

yearlings $95.31 \%$ (61/64), followed by the kids $89.16 \%$ (74/ 83 ) and adults $48.72 \%$ (38/78). Indeed, Eimeria spp. were continuously detected mixed with other infections. Moniezia spp. were the most observed concurrent infection with Eimeria spp. followed by Entamoeba spp. and Strongyle spp. (Figs. 1 and 2). Overall prevalence of Strongyle group was recorded $12.89 \%(29 / 225)$ while Moniezia spp. infection rate reached $18.22 \%(41 / 225)$. As demonstrated in Table 1, the yearling age group was significantly more susceptible to Strongyle group and Moniezia spp. infection with an incidence rate of $32.81 \%$ (21/64) for each. Furthermore, the current investigation showed that the prevalence of Entamoeba spp. infection was 26.22\% (59/225). There was significant $(P<0.05)$ high prevalence percentage between adults $62.82 \%(49 / 78)$ and yearlings $15.63 \%$ (10/64) (Table 1). Besides that, the overall prevalence of Strongyloides papillosus, Trichuris ovis, B. coli cyst, and Fasciola spp. infections reached 3.56\% (8/225), 5.33\% (12/ $225), 2.67 \%(6 / 225)$, and $0.89 \%(2 / 225)$, successively as represented in Table 1 . No significant difference $(P>0.05)$

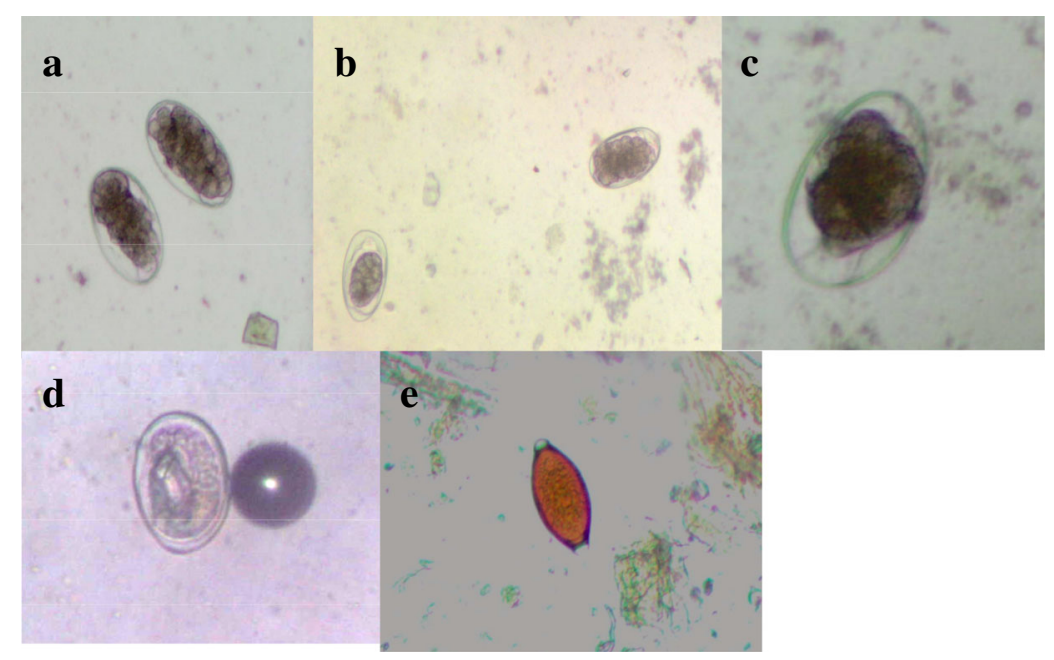

a H. contortus, b Trichostrongylus spp. and H. contortus, c Nematodirus spp., d S. papillosus, e Trichuris ovis.

Fig. 2 Shapes of different nematode eggs found in the examined goats. a H. contortus, b Trichostrongylus spp. and H. contortus, c Nematodirus spp., d S. papillosus, e Trichuris ovis 


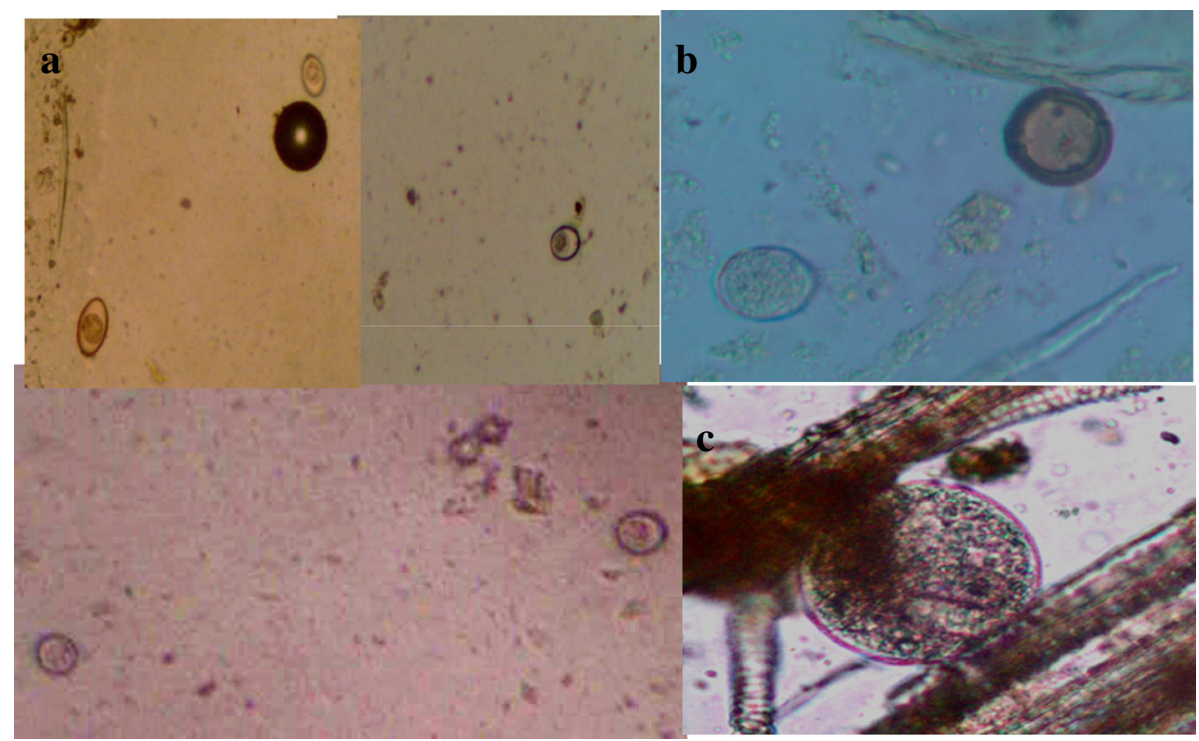

a Eimeria spp. oocyst, b E . coli cyst, c B. coli cyst.

Fig. 3 Shapes of different protozoal cysts found in goats under experiment. a Eimeria spp. oocyst, b E. coli cyst, c B. coli cyst

was recorded depending on the sex of the examined goats as shown in Table 2. The examination of GITs of the slaughtered goats showed that the prevalence of $H$. contortus was reached (10.37\%), followed by Trichostrongylus axi (6.66\%), Trichuiris ovis (4.44\%) and Monezia benedeni (14.07\%). It was found that C. tenuicollis (metacestode of Taenia hydatigena) occurred in the omentum of the intestinal tract with a percentage of $31.85 \%$.

\section{Discussion}

This study disclosed that $21.78 \%$ of the naturally infected examined goats suffered from general weakness, accompanied with watery, hemorrhagic, or mucoid diarrhea, especially those infected by coccidian and mixed

Table 1 Gastrointestinal parasitic infection percentage among different age groups of goats

\begin{tabular}{|c|c|c|c|c|c|c|c|c|c|}
\hline \multirow[t]{3}{*}{ Parasitic infection } & \multirow{3}{*}{$\mathrm{T}$} & \multirow{2}{*}{\multicolumn{2}{|c|}{$\frac{\text { Kids }}{83}$}} & \multirow{2}{*}{\multicolumn{2}{|c|}{$\frac{\text { Yearling }}{64}$}} & \multirow{2}{*}{\multicolumn{2}{|c|}{$\frac{\text { Adult }}{78}$}} & \multirow{3}{*}{$x^{2}$} & \multirow{3}{*}{ S } \\
\hline & & & & & & & & & \\
\hline & & + & $\%$ & + & $\%$ & + & $\%$ & & \\
\hline Fasciola spp. & & -- & - & 2 & 3.12 & - & - & -- & \\
\hline Monezias pp. & & 9 & 10.84 & 21 & 32.81 & 11 & 14.10 & 6.04 & $0.049^{*}$ \\
\hline Strongyle spp. & & 4 & 4.81 & 21 & 32.81 & 4 & 5.12 & 19.93 & $0.001^{*}$ \\
\hline Strongyloides spp. & & & & 2 & 3.12 & 6 & 7.69 & 2.00 & 0.157 \\
\hline Trichuris spp. & & -- & -- & 3 & 4.68 & 9 & 11.53 & 3.00 & 0.083 \\
\hline Entameoba spp & & -- & -- & 10 & 15.62 & 49 & 62.82 & 25.78 & $0.001^{*}$ \\
\hline Balantidium coli cyst & & -- & -- & 2 & 3.12 & 4 & 5.12 & 0.667 & 0.414 \\
\hline Coccidia spp. & & 74 & 89.15 & 61 & 95.31 & 38 & 48.71 & 24.08 & $0.001^{*}$ \\
\hline
\end{tabular}

$T$ Total number of examined animals, + Infected, $S$ Significance, ${ }^{*} P<0.05$ infection; these findings agree with those of Foreyt (1990), Koudela and Bokova (1998), Risso et al. (2015). The present high overall prevalence of GIP infection obtained from fecal examination $(89.33 \%)$ reflects the infection intensity among goats in Giza Governorate, Egypt. This result may be in accordance with those obtained by Singh et al. (2015) and Jena et al. (2018) who found that the prevalence of GIP infection was $86.13 \%$ in and around Ranchi, Jharkhand, India, and 94.48\% in Madhya Pradesh, India, respectively, while Negasi et al. (2012) and Das et al. (2017) observed relatively lower prevalence of goat GIP (35.33\%) in Mekelle town, northern Ethiopia, and (28.65\%) in hilly region of Meghalaya successively. Thus, GIP infection is considered a worldwide obstacle among goats. The current study proposed

Table 2 Gastrointestinal parasitic infection percentage among different six of goats

\begin{tabular}{|c|c|c|c|c|c|c|c|c|}
\hline \multirow[t]{2}{*}{ Parasitic infection } & \multicolumn{3}{|c|}{ Male } & \multicolumn{3}{|c|}{ Female } & \multirow[t]{2}{*}{$x^{2}$} & \multirow[t]{2}{*}{ S } \\
\hline & T & + & $\%$ & T & + & $\%$ & & \\
\hline Fasciola spp. & 109 & --- & --- & 116 & 2 & 1.72 & --- & --- \\
\hline Monezia pp. & 109 & 25 & 22.93 & 116 & 16 & 13.79 & 1.97 & 0.16 \\
\hline Strongyle spp. & 109 & 13 & 11.92 & 116 & 16 & 13.79 & 0.310 & 0.57 \\
\hline Strongyloides spp. & 109 & 5 & 4.58 & 116 & 3 & 2.58 & 0.50 & 0.48 \\
\hline Trichuris spp. & 109 & 8 & 7.33 & 116 & 4 & 3.44 & 1.33 & 0.24 \\
\hline Entameoba spp & 109 & 24 & 22.01 & 116 & 35 & 30.17 & 2.05 & 0.15 \\
\hline Balantidium coli cyst & 109 & 2 & 1.83 & 116 & 4 & 3.44 & 0.66 & 0.44 \\
\hline Coccidia spp. & 109 & 77 & 70.64 & 116 & 96 & 82.75 & 2.087 & 0.149 \\
\hline
\end{tabular}

$T$ Total number of examined animals, + Infected, $S$ Significance 
that enteric protozoal infections contribute heavily in the parasitic load among the examined goats. Coccidian infection was the most prevalent GIP, it was reached 76.89\%. These results agreed with the findings of Lloyd and Soulsby (1978), Penjhorn et al. (1994), Parihar et al. (1996), Obijiaku and Agbede (2007), Jatau et al. (2011), Singh et al. (2015), Verma et al. (2018) who reported high incidence of coccidian infection. In the current investigation, no pure infection of Eimeria spp. could be found among the infected goats; it always subsists mixed with other species which agreed with the prevailed condition of polyparasitism recorded by Alyousif et al. (1992) and Khan et al. (2000). This may be attributed to the exposure of the goats to contaminated pasture by different types of parasites. Relatively higher Entamoeba spp. prevalence (26.22\%) was documented in the examined goats than those obtained by Mhoma et al. (2011) in Mwanza City, Tanzania (6.3\% in peri-urban and 3.2\% in urban areas), and Sultan et al. (2016) in Kafrelsheikh Governorate, Egypt (10.27\%). Indeed, Entamoeba, namely E. polecki and E. histolytica, have been proved to be pathogenic to both humans and animals (Schuster and Visvesvara 2004). It is found that large populations of Entamoeba coli (E. coli) may cause gastrointestinal disturbance (Saritha 2015). Another important protozoal parasite, B. coli (cysts and trophozoites), which is the causative agent of zoonotic important balantidiasis was found in $2.66 \%$ of the examined goats. This result was in accordance with those obtained by Kanyari et al. (2009), Mhoma et al. (2011), Jamil et al. (2014), and Sultan et al. (2016) who showed that prevalence of balantidiasis was $3 \%, 4.8 \%, 3.46 \%$, and $1.79 \%$ respectively. However, it was in contrary to Elmadawy and Diab (2017) who mentioned that the total prevalence of goat balantidiasis was $7.1 \%$. To our knowledge, in Egypt, a few studies recorded goat balantidiasis. This study presumed that goats may be infected by $B$. coli via infected animals reared in the same herd and as a result of exposure to contaminated water and pasture sources by human or animal excretions in the free-range rearing system (Kijlstra et al. 2009).

On the other hand, the adult cestodes identified through fecal examination in this study were Moniezia spp. with a prevalence of $18.22 \%$. Similar results showed that the prevalence of Moniezia spp. among goats was 19.04\% (Sultan et al. 2010), 15.09\% (Negasi et al. 2012), 10\% (Das et al. 2017), and 18.74\% (Verma et al. 2018). However, Sultan et al. (2016) reported much lower prevalence of Moniezia spp. $0.89 \%$ in sheep. The apparition of this parasite in the tropics is associated with the ingestion of oribatid mite intermediate host which is infected with larvocysts of Moniezia spp. (Diop et al. 2015) . In the current study, it was cleared that among the GI nematodes, Strongyle group infection was more pronounced $(12.89 \%)$. These results were in line with those reported by Sultan et al. (2016) who found that the Strongyle group infection prevalence was 19.21\%. However, Singh et al. (2015) and Zvinorova et al. (2016) recorded much high prevalence (69.27 and 31\%, respectively). The low prevalence of Trichuris ovis (5.33\%) observed in this study was consistent with those obtained by Nwigwe et al. (2013) and Singh et al. (2015) as 2.43\% and $3.85 \%$, successively. However, it disagreed with the findings of Negasi et al. (2012) who recorded relatively higher Trichuris spp. prevalence (45.28\%). Besides that, the present prevalence of Strongyloides papillosus (3.55\%) was more or less different from those stated by Singh et al. (2015), Yusof and Isa (2016), Das et al. (2017), and Verma et al. (2018) who mentioned that $9.17 \%, 45.6 \%, 8.91 \%$, and $0.70 \%$ of goats were infected by Strongyloides papillosus successively. Yadav (2000) declared that humid tropical environment has been considered favorable for the development of various species of nematodes. Infection by liver fluke (Fasciola spp.) was of the lowest prevalence $(0.89 \%)$ among examined goats. This finding was closely related to those of Sultan et al. (2010) who reported that $0.53 \%$ of sheep were infected by Fasciola spp. While Negasi et al. (2012) recorded much higher prevalence of Fasciola spp. 20.75\%. These variations may be due to proper and progressive application of control measures against fasciolosis in Egypt (Youssef and Uga 2014). Regarding age, wise analysis of data showed that there were significant differences $(P<$ 0.05 ) between the three age groups. The prevalence of Entamoeba spp. infection in the adult age group was significantly higher than the corresponding values in young age groups. These results might be returned to various stressful factors such as lactation or pregnancy might contribute in the suppression of host immune status and leading to increase the prospect of infection (Roy et al. 2011). On other hand, the prevalence of Coccidian spp., Strongyles spp., and Moniezia spp. in the young age groups was significantly higher than those in the adult age group. These results coincided with those obtained by Emiru et al. (2013), El-Shahawy (2016), and Verma et al. (2018) that may be owing to less developed immunity among young ages in contrast to the adults of low incidence rate due to the well-developed resistance. This study disclosed that higher prevalence of parasitic infection was not incorporated with sex $(P>0.05)$. This may resemble the results obtained by Jittapalapong et al. (2012) and Verma et al. (2018). However, other studies were contrary to this result and recorded that female goats appear to be more susceptible than male goats to parasitic infections (Alexander and Stinson, 1988; Tariq et al. 2008 and Zvinorova et al. 2016). It is supposed that fecal examination-based survey was considered a good diagnostic tool for the most epidemic parasites in the 
investigation areas (El-Shahawy 2016). The postmortem examination revealed that $H$. contortus was the most prevalent nematode followed by $T$. axei and T. ovis. This agrees with the data obtained by Kagira and Kanyari (2001) and Ntonifor et al. (2013) who mentioned that Haemonchus spp. have been considered a cause of serious pathogenic effects including gastroenteritis, poor growth rates, and even mortalities among young age. Regarding the prevalence of $C$. tenuicollis in goats (31. $85 \%$ ), the present study more or less resembles the findings obtained by Pathak and Gaur (1982) $27.29 \%$ in India, Nwosu et al. (1996) 34.2\% in Nigeria, and Radfar et al. (2005) $18.04 \%$ in Iran. However, higher prevalence rates of infection were recorded. Sissay et al. (2008) in eastern Ethiopia reported that $53.0 \%$ goats were infected by $C$. tenuicollis, and Oryan et al. (2012) recorded higher infection rate of $55.05 \%$ in Iran. The prevalence of metacestode infection among goats in the current study might be owing to high population of stray dogs in the grazing area of ruminants. Also, feeding offal of ruminants to dogs causes completion of the life cycle.

\section{Conclusions}

It is concluded that the present study provides a basic data about the most prevalent GIP diseases among goats in Giza Governorate, Egypt. The high overall prevalence of GIP declares the infection intensity among goats. Single or mixed infections of coccidiosis are more prevalent parasitic disease in the examined region. Parasitic loads have adverse effects on goat industry and public health. Fecal examination and postmortem findings-based survey remain of choice particularly in the deprived investigation areas. So, the periodical assessment of the prevalence of the GIP infectious diseases among goat farms is a necessitate to monitor the affectivity of the used preventive and control programs.

\section{Abbreviations}

GIP: Gastrointestinal parasites; GIT: Gastrointestinal tract; spp.: Species

\section{Acknowledgements}

The authors duly acknowledge the support and technical help offered from the Parasitology and Animal diseases Department, Veterinary branch, National Research Centre.

\section{Authors' contributions}

NMFH designed, supervised, and directed the experiment. NMFH, TKF, NMTA, and HAAA collected and carried out the laboratory work of the samples. NMFH, TKF, NMTA, and HAAA analyzed and discussed the resultant data. NMFH wrote the manuscript. NMFH, NMTA, and HAAA revised and reviewed the manuscript for publication. All authors read and approved the final manuscript.

\section{Funding}

This work was financially supported by the National Research Centre as a part of the project No.11020303 - the 11th research plan under the supervision of Prof. Dr. Hala Abo-Ziena.

\section{Ethics approval and consent to participate}

The experiments were conducted in compliance with the requirements and recommendations of the Ethical Committee of the National Research Centre and the current Egyptian Law and Regulations that assigned for the protection of the experimental animals to minimize the negative states (harms) and improve feeding and housing conditions under certificate number (16229). All authors read and approved the final manuscript.

Consent for publication

Not applicable.

\section{Competing interests}

The authors declare that they have no competing interests.

Received: 25 January 2019 Accepted: 20 June 2019

Published online: 01 August 2019

\section{References}

Aboul-Naga AM, Hamed A, Shaat I, Mabrouk MMS (2012) Genetic improvement of Egyptian Nubian goats as sub-tropical dairy prolific breed. Small Rum Res 102(2-3):125-130

Agyei A, Modonkor D, Osei-somuah A (2004) Concurrence of Eimeria and helminth parasitic infections in west African dwarf kids in Ghana. Small Rum. Res 51:29-35

Aidaros H (2005) Global perspectives-the Middle East: Egypt. Rev Sci Tech Off Int Epiz 24:589-596

Alexander J, Stinson WH (1988) Sex hormones and the course of parasitic infection. Parasitol Today 4:189-193

Alyousif MS, Kasim AA, Al-shawa YR (1992) Coccidia of the domestic goat (Capra hircus) in Saudi Arabia. Int J Parasitol 22:807-811

Badran I, Abuamsha R, Aref R, Alqisi W, Alumor J (2012) Prevalence and diversity of gastrointestinal parasites in small ruminants under two different rearing systems in Jenin district of Palestine. An-Najah Univ J Res 26:1-18

Di Cerbo AR, Manfredi, M, Zanzani S, Stradiotto K (2010) Gastrointestinal infection in goat farm in Lombardy (Northern Italy): analysis on community and spatial distribution of parasites. Small Rum Res 88:102-112

Das M, Laha R, Goswami A, Goswami A (2017) Gastrointestinal parasitism of goats in hilly region of Meghalaya, India. Vet World 10(1):81-85

Diop G, Yanagida T, Hailemariam Z, Menkir S, Nakao M, Sako Y, Ba CT, Ito A (2015) Genetic characterization of Moniezia species in Senegal and Ethiopia. Parasitol Int 64(5):256-260

Elmadawy R S, Diab M S (2017) Prevalence of Balantidium coli and molecular analysis of Isospora oocysts found in goats in Qalyobia Governorate, Egypt. Ann Vete and Anim Sci http://naturepub.org/navas [Received: 20 Oct 16, Accepted: 11 Jan 17, Published: 28 Feb 17]

El-Shahawy IS (2016) Coproscopic study on enteric protozoan parasites of goats (Capra hircus L., 1758) in Upper Egypt. Pakist J zool 48(5):1477-1483

Emiru B, Amede Y, Tigre W, Feyera T, Deressa B (2013) Epidemiology of gastrointestinal parasites of small ruminants in Gechi District, Southwest Ethiopia. Adv Biol Res 7:169-174

Foreyt WJ (1990) Coccidiosis and cryptosporidiosis in sheep and goats. Vet Clin North Am Food Anim Pract 6(3):655-670

Gadelhaq SM, Arafa WM, Aboelhadid SM (2015) Molecular characterization of Eimeria species naturally infecting Egyptian Baldi chickens. Iran J Parasitol 10(1):87-95

Githigia SM, Thamsborg SM, Munyua WK, Maingi N (2001) Impact of gastrointestinal helminths on production in goats in Kenya. Small Rum Res 42:21-29

Jamil M, ljaz M, Muddassir AM (2014) Prevalence, hematology and treatment of Balantidium coli among small ruminants in and around Lahore, Pakistan. Kafkas Univ Vet Fak Derg 21:123-126

Jatau ID, Abdulganiyu A, Lawal AL, Okubanjo OO, Yusuf KH (2011) Gastrointestinal and haemoparasitism of sheep and goats at slaughter in Kano, northern-Nigeria. Sokoto J Vet Sci 9(1):7-11

Jena A, Deb AR, Kumari L, Biswal SS, Joshi SK (2018) Prevalence of gastrointestinal helminthes among goats in and around Ranchi, Jharkhand, India. Int J Curr Microbiol App Sci 7(1):3506-3513

Jittapalapong S, Saengow S, Pinyopanuwat N, Chimnoi W, Khachaeram W, Stich RW (2012) Gastrointestinal helminthic and protozoal infections of goats in Satun, Thailand. J Trop Med Parasitol 35:48-54 
Jurasek ME, Bishop-Stewart JK, Storey BE, Kaplan RM, Kent ML (2010) Modification and further evaluation of a fluorescein-labeled peanut agglutinin test for identification of Haemonchus contortus eggs. Vet Parasitol 169(1):209-213

Kagira JM, Kanyari PWN (2001) The role of parasitic diseases in causing mortalities in small ruminants in a highly productive area of Central Province, Kenya. J S Afr Vet Assoc 72:147-149

Kanyari PWN, Kagira JM, Mhoma RJ (2009) Prevalence and intensity of endoparasites in small ruminants kept by farmers in Kisumu Municipality, Kenya. Livestock Res Rural Develop 21:1-10

Khan RM, Shaikh AA, Khan MM (2000) Natural infection with Eimeria species (Ampicomplexa: Eimeriidae) in indigenous fowls of Hyderabad district of Sindh province (Pakistan). Pakistan J Zool 32:11-14

Kijlstra A, Meerburg B, Bos A (2009) Food safety in free-range and organic livestock systems: risk management and responsibility. J Food Protect 72: 2629-2637

Koudela B, Bokova A (1998) Coccidiosis in goats in the Czech Republic. Vet Parasitol 76(4):261-267

Kusiluka L J M, Kambarage D M, Harrison L J S, Daborn C J, Matthewman R W (1998) Causes of morbidity and mortality in goats in Morogoro district, Tanzania: the influence of management 29:167-172

Lloyd S, Soulsby EJL (1978) Survey of parasites in dairy goats. Am J Vet Res 39: 1057-1059

Majeed QA, Alazemi MS, Henedi AA, Tahrani LM (2015) Study on parasites from farm animals in Kuwait. J Egypt Soc Parasitol 45(1):71-74

Mhoma JRL, Kanyari PWN, Kagira JM (2011) The prevalence of gastrointestinal parasites in goats in urban and peri-urban areas of Mwanza City, Tanzania. Scient Parasitol 12:191-196

Mohamaden W, Sallamc NH, Abouelhassan EM (2018) Prevalence of Eimeria species among sheep and goats in Suez Governorate, Egypt. Int J Vet Sci Med. https://doi.org/10.1016/j.ijvsm.2018.02.004

Negasi W, Bogale B, Chanie M (2012) Helminth parasites in small ruminants: prevalence, species composition and associated risk factors in and around Mekelle town, Northern Ethiopia. Eur J Biol Sci 4(3):91-95

Ntonifor H, Shei S, Ndaleh N, Mbunkur G (2013) Epidemiological studies of gastrointestinal parasitic infections in ruminants in Jakiri, Bui division, North West region of Cameroon. J. Vet. Med. Anim. Health. 5(12):344-352

Nwigwe JO, Njoku OO, Odikamnoro OO, Uhuo AC (2013) Comparative studies of intestinal helminthes and protozoa of cattle and goats in Abakaliki metropolis of Ebonyi State, Nigeria. Adv Appl Sci Res 4:223-227

Nwosu CO, Ogunrinade AF, Fagbemi BO (1996) Prevalence and seasonal changes in the gastro-intestinalhelminths of Nigerian goats. J Helminthol 70:329-333

Obijiaku I N, Agbede R I S (2007) Prevalence of coccidiosis and associated pathology in lambs and kids from three contrasting management systems. In: Proceedings of the 44th Annual Congress of the Nigerian Veterinary Medical Association (NVMA), Delta 2007 pp 229-232

Oryan A, Goorgipour S, Moazeni M, Shirian S (2012) Abattoir prevalence, organ distribution, public health and economic importance of major metacestodes in sheep, goats and cattle in Fars, southern Iran. Trop Biomed 29(3): 349-359. PMid:23018497

Parihar M G, Manohar G S, Pathak K M L Kumar D (1996) Prevalence of gastrointestinal parasitosis in goats in and around Ramsar, Rajasthan. 8th National Congress of Vete Parasitol, Hissar, 9-11 October 36

Pathak KM, Gaur SNS (1982) The incidence of adult and larval stage Taenia hydatigena in Pradesh (India). Vet Parasitol 10:91-95

Penjhorn BK, Rognile MC, Hall LL, Kemp SE (1994) Enteric coccidian of Cashmere goats in southwestern Montana, USA. Vet Parasitol 55:137-142. https://doi. org/10.1016/0304-4017(94)90064-7

Perry BD, Randolph TF, McDermott JJ, Sones KR, Thornton PK (2002) Investing in animal health research to alleviate poverty. International Livestock Research Institute (ILRI), Nairobi, p 148

Radfar MH, Tajalli S, Jalalzadeh M (2005) Prevalence and morphological characterization of Cysticercus tenuicollis (Taenia hydatigena cysticerci) from sheep and goats in Iran. Veterinarski Arhiv 75:469-476

Radostits OM, Blood DC, Gay CC, Hinchcliff KW (2000) Veterinary Medicine: a textbook of the diseases of cattle, sheep, goats and horses: 9th Ed. Bailliere Tindall, Philadelphia, pp 3-37

Rahman MH, Soliman KN, Shaikh H (1975) Proceedings of Pakistan Scientific Conference, University of Peahwar 17

Ratanapob N, Arunvipas P, Kasemsuwan S, Phimpraphai W, Panneum S (2012) Prevalence and risk factors for intestinal parasite infection in goats raised in Nakhom Pathom Province, Thailand. Trop Anim Health Prod 44:741-745
Risso A, Kessler JD, Soriano VS, Nunes MLA, Machado G, Langaro A, Rossetto R, Zuffo T, Dallago M, Castro P (2015) Influence of pathological conditions caused by gastrointestinal parasites infection on pregnant ewe's behavior. Acta Sci Vet 43:1283

Roy BC, Mondal MMH, Talukder MH, Majumder S (2011) Prevalence of Balantidium coli in Buffaloes at different areas of Mymensingh. J of Bangl Agric Univ 9(1):67-72

Saritha P (2015) Parasite Entamoeba histolytica : life cycle, mode of infection and treatment. Yourarticlelibrary.com. Retrieved 2015-12-03.

Schuster FL, Visvesvara GS (2004) Free-living amoebae as opportunistic and nonopportunistic pathogens of humans and animals. Int J Parasitol 34(9):1001-1027

Singh AK, Das G, Roy B, Nath S, Naresh R, Kumar S (2015) Prevalence of gastrointestinal parasitic infections in goat of Madhya Pradesh, India. J Parasit Dis. 39(4):716-719

Sissay MM, Uggla A, Waller PJ (2008) Prevalence and seasonal incidence of larval and adult cestode infections of sheep and goats in eastern Ethiopia. Trop Anim Health Prod 40:387-394

Soliman MFM, Zalat SM (2003) Prevalence and intensity of Nematodirus sp. and Eimeria sp. infections in the domestic goats of St. Katherine's Protectorate (Sinai, Egypt): Relations with some ecological and biological factors. Egypt J Biol 5:78-85

Soulsby EJL (1982) Helminths, arthropods and protozoa of domesticated animals. Bailliere and Tindal, London

Soulsby EJL (1986) Helminths, arthropods and protozoa of domesticated animals. 7th ed. London: Bailliere Tindall

Sultan K, Desoukey A, Elsiefy M, Elbahy N (2010) An abattoir study on the prevalence of some gastrointestinal helminths of sheep in Gharbia Governorate, Egypt. Global Vet 5:84-87

Sultan K, Elmonir W, Hegazy Y (2016) Gastrointestinal parasites of sheep in Kafrelsheikh governorate, Egypt: prevalence, control and public health implications. Beni-Suef Univ J Basic Appl Sci 5(1):79-84

Tariq K, Chishti M, Ahmad F, Shawl A (2008) Epidemiology of gastrointestinal nematodes of sheep managed under traditional husbandry system in Kashmir valley. Vet Parasitol 158(1):138-143

Taylor EL (1934) Animal Trop Med Parasites 19(1):57

Urquhart GM, Armour J, Duncan JL, Dunn AM, Jennings FW (1996) Vete Parasitol. 2nd. Wiley-Blackwell, Glasgow, pp 3-137

Verma R, Sharma DK, Paul S, Gururaj K, Dige M, Saxena VK, Rout PK, Bhusan S, Banerjee PS (2018) Epidemiology of common gastrointestinal parasitic infections in goats reared in semi-arid region of India. J Anim Res 8(1): 39-45

Waller PJ (1999) International approaches to the concept of integrated control of nematode parasites of livestock. Int J Parasitol 29:155-164

Yadav CL (2000) Agro-climatic influence on parasitic disease of sheep and goats. Pashudhan 15:1

Youssef A, Uga S (2014) Review of parasitic zoonoses in Egypt. Trop Med Health 42:3-14

Yusof AM, Isa MLM (2016) Prevalence of gastrointestinal nematodiasis and coccidiosis in goats from three selected farms in Terengganu, Malaysia. Asian Pac J Trop Biomed 6(9):735-739

Zvinorova PI, Halimani TE, Muchadeyi FC, Matika O, Riggio V, Dzama K (2016) Prevalence and risk factors of gastrointestinal parasitic infections in goats in low-input low-output farming systems in Zimbabwe. Small Rum Res 143:75-83

\section{Publisher's Note}

Springer Nature remains neutral with regard to jurisdictional claims in published maps and institutional affiliations. 